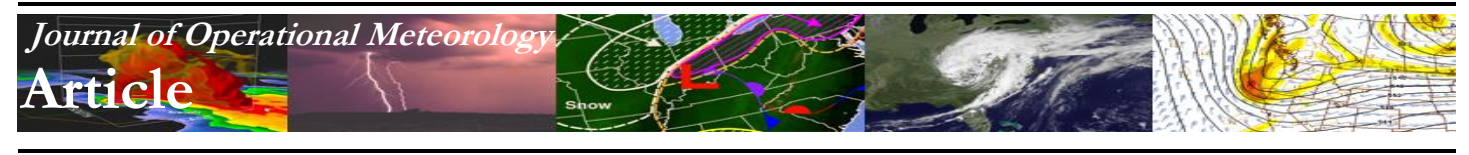

\title{
Characteristics of Major Ice Storms in the Central United States
}

\author{
KRISTOPHER J. SANDERS \\ NOAA/National Weather Service, Topeka, Kansas \\ CHAD M. GRAVELLE \\ Cooperative Institute for Meteorological Satellite Studies, University of Wisconsin-Madison, Madison, Wisconsin \\ National Weather Service Operations Proving Ground, Kansas City, Missouri \\ JOHN P. GAGAN \\ NOAA/National Weather Service, Springfield, Missouri \\ CHARLES E. GRAVES \\ Department of Earth and Atmospheric Science, Saint Louis University, St. Louis, Missouri
}

(Manuscript received 13 February 2013; in final form 25 June 2013)

\begin{abstract}
A 30-yr (1979-2009) climatology of major ice storms with $19.05 \mathrm{~mm}(0.75 \mathrm{in})$ ice accumulation or greater across the central United States is presented. An examination of the United States Army Cold Regions Research and Engineering Laboratory Ice Storm Database, in conjunction with National Climatic Data Center Storm Data, revealed 20 (out of 51) ice storms during the period which satisfied the selection criteria herein. Using the General Meteorological Package with the North American Regional Reanalysis dataset, system-relative composites using both traditional (i.e., mean) and probabilistic (i.e., frequency analysis of median, quartiles, and threshold exceedance) composite-analysis measures for the major ice storms were created. The composite analysis was computed at start, maximum coverage, and end times to depict the evolution of features used to diagnose the synoptic and mesoscale environment potentially favorable for major ice storms within the central United States.

At the maximum-coverage time, the composite analysis indicates the presence of sub-freezing surface temperatures to the north of a southwest-to-northeast oriented quasi-stationary front below a strong 850-hPa jet streak. The low-level jet streak bisects the quasi-stationary front and is enhanced by the direct thermal circulation associated with an upper-level jet streak. These features are responsible for supplying warm and moist air into the elevated warm layer, which provides an environment to completely melt frozen precipitation. An upper-level long-wave trough is anchored over the southwestern United States and there is some evidence that it leads to short-wave troughs ejecting into the plains. These troughs may be responsible for multiple rounds of enhanced vertical motion, precipitation, and freezing rain. Finally, an analysis of probabilistic measures of the 300- and $850-\mathrm{hPa}$ jet streaks and elevated warm-layer characteristics indicates the importance of these fields in major ice storms in this region.
\end{abstract}

\section{Introduction}

Major ice storms are high-impact weather events capable of devastating critical infrastructure and property. Furthermore, the accumulation of freezing rain on roads, sidewalks, and railways results in significant hazards for all types of transportation. Branick (1997) found that significant freezing rain or drizzle occurs in about $24 \%$ of all winter weather events in the continental United States and one-half of these events meet ice-storm requirements based on National Weather Service (NWS) criteria [i.e., ice accumulations of at least $6.35 \mathrm{~mm}(0.25$ in)]. Moreover, insured property losses from ice-storm catastrophes average \$326 million annually (Changnon 2002). 
From 2006-2010, an area extending from the central plains through the mid-Mississippi and Ohio River Valleys (Fig. 1) has experienced seven ice storms (i.e., extensive damage to trees and power lines). After the 27-29 January 2009 ice storm, over two million people were without power, and federal disaster declarations were made in seven states from Oklahoma to Kentucky. The ice storm of 12-14 January 2007 cost the state of Missouri \$35 million in recovery efforts. These high-impact events illustrate the importance of identifying major ice storms days in advance. However, these events create difficult forecast problems due to the subtle juxtaposition of air masses coupled with their relative infrequency of occurrence. While winter storms susceptible to freezing precipitation are closely monitored by forecasters, mesoscale aspects of these events make the precise location and severity of freezing rain difficult to forecast (Czys et al. 1996; Rauber et al. 2001).

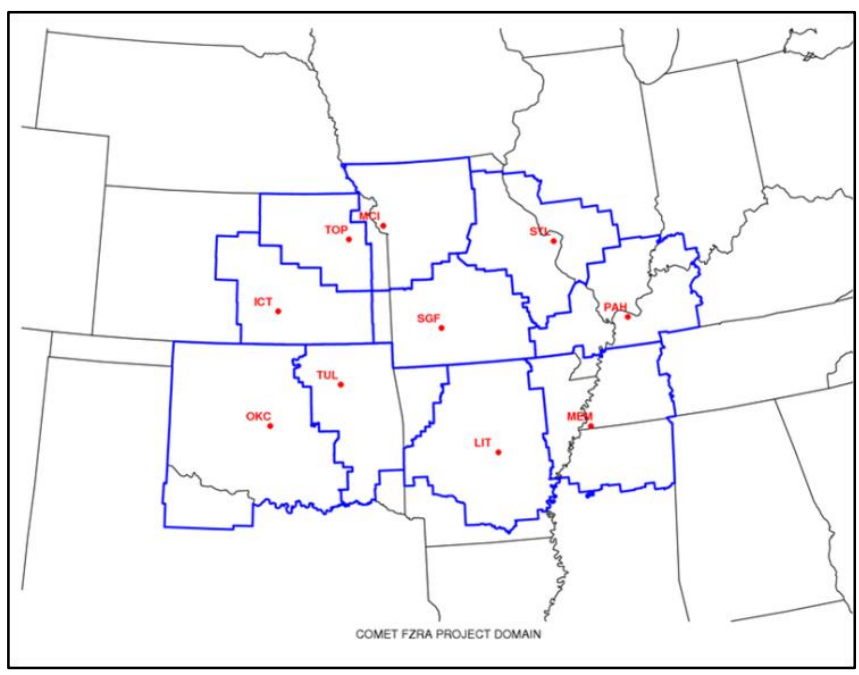

Figure 1. Study domain NWS county warning areas: Kansas City/Pleasant Hill, MO (MCI); Little Rock, AR (LIT); Memphis, TN (MEM); Norman, OK (OKC); Paducah, KY (PAH); St. Louis, MO (STL); Springfield, MO (SGF); Topeka, KS (TOP); Tulsa, OK (TUL); and Wichita, KS (ICT). Click image for an external version; this applies to all figures hereafter.

Past research has identified several regions in the United States that are susceptible to freezing-rain events (see Cortinas et al. 2004 and references therein). A climatology of the frequency of freezing precipitation from Cortinas et al. (2004) shows a broad maximum in freezing-precipitation frequency extending along an axis from the Texas Panhandle to Michigan. Rauber et al. (2001), using a geographic distribution of 972 freezing-rain soundings over a 25- yr period, revealed a local maximum in freezing-rain frequency across the western and central plains from Oklahoma and Kansas into Illinois. Changnon and Karl (2003), using a database from 1948-2000 of average and extreme freezing-rain-day values, identified an elongated zone with annual averages of five days or more extending from Missouri to western Pennsylvania.

Freezing-rain environments, and in particular the vertical profile of freezing-rain events, have been analyzed extensively. Bernstein (2000) used $48 \mathrm{yr}$ of radiosonde data from six sites to identify important regional and local influences on freezing precipitation in the United States. He determined that the thermodynamic profile during freezing rain usually had an elevated warm layer with a depth of up to 2800 $\mathrm{m}$, and a maximum temperature within the layer that ranged from $1{ }^{\circ} \mathrm{C}$ to $10^{\circ} \mathrm{C}$. Below the warm layer was a sub-freezing layer, which had a depth of up to $1400 \mathrm{~m}$, and a minimum temperature within the layer that ranged from $-1^{\circ} \mathrm{C}$ to $-7^{\circ} \mathrm{C}$. Similarly, Robbins and Cortinas (2001) found that the elevated warm layer had a median maximum temperature of $3.2^{\circ} \mathrm{C}$ at a height of $1100 \mathrm{~m}$ and depth of $1300 \mathrm{~m}$. Rauber et al. (2001) also observed that the depth of this warm layer was well correlated with the maximum temperature in the layer. However, they found that the near-surface minimum temperature, which was nearly always above the surface, was poorly correlated with the cold-layer depth. On average, the lowest temperature in the cold layer was $2.6^{\circ} \mathrm{C}$ lower than the surface temperature. Furthermore, the coldest temperature in the cold layer was typically between $200-600 \mathrm{~m}$ above the ground, with an average height of $419 \mathrm{~m}$.

From hourly surface observations during freezingrain events, Robbins and Cortinas (2001) observed that surface thermal advection was typically weak at the time of freezing rain, suggesting that the surface cold layer was firmly established by the time precipitation began. While Bernstein (2000) and Robbins and Cortinas (2001) found that warm-air advection was primarily responsible for producing the elevated warm layer, Robbins and Cortinas (2001) estimated that warm advection usually reached a maximum near 850 $\mathrm{hPa}$.

Additionally, the impacts of hydrometeors falling through both the elevated warm layer and near-surface cold layer have been examined. Stewart and King (1987) studied the melting behavior of snowflakes as they fell through the atmosphere using a numerical model based on the empirical melting rates of 
snowflakes as described by Stewart et al. (1985). For maximum warm-layer temperatures $>3.8^{\circ} \mathrm{C}$, all snowflakes having a mass as large as a 4-mm diameter raindrop completely melted. Stewart and Crawford (1995) determined that ice nucleation could lead to completely melted droplets refreezing in the cold layer in the presence of sufficiently cold temperatures (less than $-5^{\circ} \mathrm{C}$ ). Zerr (1997) found by investigating soundings during ice-pellet events that temperatures in the cold layer were $<-5^{\circ} \mathrm{C}$, and depths were $>700 \mathrm{~m}$. Czys et al. (1996) were able to identify regions of freezing rain and ice pellets for the $1990 \mathrm{St}$. Valentine's Day ice storm using a non-dimensional parameter that takes into consideration the time required for ice particles to melt in an elevated layer of above-freezing air.

Rauber et al. (2001) and Robbins and Cortinas (2001) also examined the spatial patterns associated with freezing-rain events. For those events in the central United States (most relevant to this study) the dominant pattern was associated with an Arctic front and an anticyclone where the isentropic lift across the frontal zone provided the mechanism for the formation of the elevated warm layer. The other patterns were less common and associated with a cyclonic system. Robbins and Cortinas (2001) also noted that the classic synoptic-scale lift (i.e., $850-500-\mathrm{hPa}$ differential vorticity advection) was more prevalent in the freezing-rain events associated with cyclonic systems.

These past studies of freezing-rain events have focused on the frequency of the occurrences, geographic distributions, thermal profiles, and classifications of the environments. These studies mainly used soundings, surface-analysis charts, and hourly surface observations pertaining to certain regions in the United States. There is less research regarding the evolution of the synoptic and mesoscale features associated with ice storms. This paper will focus on the characteristics of ice storms in the central United States by using a system-relative compositeanalysis methodology and the North American Regional Reanalysis (NARR; Mesinger et al. 2006). Consequently, the synoptic and mesoscale patterns, maintenance of the surface cold layer, and the evolution of the elevated warm layer can be investigated. Furthermore, the specific areas-relative to the overall system - which are more likely to have significant freezing rain occur given this typical pattern, can be identified. Recognizing the environmental conditions associated with ice storms enhances situational awareness, which will aid in mobilizing preparation efforts by emergency managers; city, county, and state road crews; and the general public - thereby lessening the impact of these events.

\section{Data and methods}

Past research (e.g., Rauber et al. 2001) has identified southern Missouri as a region with a relatively high frequency of freezing rain. Therefore, the domain for this study was centered on southern Missouri and included the ten NWS county warning areas (CWAs) depicted in Fig. 1. This domain was chosen to be large enough to capture enough ice storms in order to enhance the representativeness of the composites, but not too large so that regional and geographical differences impacted the results. Examining the ice-storm database from the Cold Regions Research and Engineering Laboratory, Storm Data from the National Climatic Data Center, and event archives from the ten NWS Weather Forecast Offices, 51 ice storms were identified with $6.35 \mathrm{~mm}$ (0.25 in) ice accumulation or greater within the domain from January 1979 to March 2010. All measurements of ice accumulations from each event were documented, but ultimately the reported event maximum ice-accumulation measurements were used for classification purposes. This procedure for identifying cases preferentially selects events that are large-scale and high-impact.

The duration of all the events was determined from hourly standard NWS observations. The start date/time was the first hour in which there were two or more freezing-rain observations within the domain and the end date/time was the hour at which there were no freezing-rain observations within the domain. The list of all 51 events, their start dates, duration, and maximum ice accumulation are provided in Table 1 . The majority of events occurred in the heart of the winter season with $80 \%$ of the storms in the months December through February. The duration of the events across the entire domain (not at a single location) ranged from 9-99 $\mathrm{h}$; however, the duration for $70 \%$ of the events was between 15-40 h. Finally, to capture the environment during the storm's mature phase, a maximum-coverage date/time was determined for each event. This date and time was the first hour when the most freezing-rain observations were reported within the domain. The maximum-coverage time was on average $12-18 \mathrm{~h}$ after the start time, but ranged from 3-27 h. 
Table 1. List of ice storms [NWS $6.35-\mathrm{mm}(0.25$ in) threshold] identified from 1979-2010 that affected the central United States. Events in boldface (20, also see Fig. 2) were associated with an ice accumulation of $19.05 \mathrm{~mm}(0.75 \mathrm{in})$ or greater and a $2-\mathrm{m} 0^{\circ} \mathrm{C}$ isotherm oriented southwest-northeast, and thus were chosen for the composite analysis. Date/time format is YYYY-MM-DD HH, where $\mathrm{HH}$ is in UTC.

\begin{tabular}{|c|c|c|}
\hline Start date/time & Duration (h) & Maximum ice (in) \\
\hline $1979-01-0613$ & 28 & 3.00 \\
\hline 1983-01-19 10 & 80 & 1.00 \\
\hline $1985-02-0420$ & 16 & 0.50 \\
\hline 1985-12-09 16 & 47 & 1.00 \\
\hline 1987-01-16 08 & 73 & 1.00 \\
\hline $1987-02-1519$ & 46 & 1.50 \\
\hline $1987-12-1422$ & 07 & 0.50 \\
\hline 1987-12-25 09 & 49 & 3.00 \\
\hline $1988-03-0308$ & 26 & 1.50 \\
\hline 1989-03-04 13 & 51 & 1.00 \\
\hline 1990-02-14 13 & 31 & 1.75 \\
\hline $1990-12-2016$ & 65 & 1.00 \\
\hline $1991-10-3104$ & 34 & 2.00 \\
\hline 1993-02-24 16 & 27 & 0.25 \\
\hline $1994-01-1613$ & 22 & 2.00 \\
\hline 1994-02-08 11 & 35 & 0.50 \\
\hline 1994-02-22 09 & 20 & 1.50 \\
\hline $1995-01-0523$ & 20 & 1.00 \\
\hline $1997-01-1502$ & 16 & 1.00 \\
\hline $1997-12-2108$ & 20 & 0.75 \\
\hline $1998-03-1609$ & 32 & 1.00 \\
\hline 1998-12-23 12 & 13 & 0.75 \\
\hline 1999-01-01 09 & 33 & 1.00 \\
\hline 1999-01-08 00 & 24 & 0.50 \\
\hline 1999-01-1307 & 11 & 0.50 \\
\hline $2000-11-0815$ & 24 & 1.00 \\
\hline $2000-12-1023$ & 18 & 0.50 \\
\hline $2000-12-1305$ & 22 & 3.00 \\
\hline $2000-12-1513$ & 18 & 0.50 \\
\hline $2000-12-2510$ & 56 & 3.00 \\
\hline $2001-01-2721$ & 42 & 1.00 \\
\hline 2001-02-21 14 & 19 & 0.75 \\
\hline 2002-01-2914 & 70 & 2.00 \\
\hline 2002-03-02 01 & 13 & 0.25 \\
\hline $2002-03-2506$ & 33 & 0.50 \\
\hline 2002-12-03 19 & 39 & 2.00 \\
\hline 2003-02-26 06 & 16 & 0.75 \\
\hline $2004-01-2507$ & 21 & 1.00 \\
\hline 2005-01-04 11 & 44 & 1.00 \\
\hline $2006-02-1802$ & 23 & 0.25 \\
\hline 2006-11-29 17 & 44 & 2.00 \\
\hline 2007-01-12 11 & 73 & 2.00 \\
\hline 2007-12-08 12 & 99 & 3.00 \\
\hline $2008-02-1113$ & 35 & 1.00 \\
\hline $2008-02-2108$ & 26 & 0.75 \\
\hline $2008-03-0318$ & 26 & 0.50 \\
\hline $2008-12-1521$ & 34 & 0.25 \\
\hline 2009-01-05 17 & 19 & 0.50 \\
\hline $2009-01-2617$ & 37 & 2.00 \\
\hline 2009-03-27 18 & 38 & 0.75 \\
\hline 2010-01-28 14 & 30 & 1.50 \\
\hline
\end{tabular}

To focus on the most destructive events (hereafter termed major), only the 37 events reporting a maximum ice accumulation of $19.05 \mathrm{~mm}(0.75 \mathrm{in})$ or greater were included in any further analysis, and the environments associated with these events were analyzed using the NARR. In order to classify the events, each event was grouped according to the orientation of the $2-\mathrm{m} 0^{\circ} \mathrm{C}$ isotherm at the start date/ time. Of the 37 events, 24 were oriented southwest-tonortheast, 7 from west-to-east, and 6 from northwestto-southeast. Examining the overall synoptic patterns associated with the 24 southwest-to-northeast events revealed that 20 of the cases were associated with an Arctic front/anticyclone - the most common weather pattern associated with freezing precipitation identified by Rauber et al. (2001). The other four cases were associated with a cyclonic system and were considered synoptically different from the other 20 events. Therefore, these 20 major ice storms (highlighted in Table 1) were the focus of the study and used in the composite analysis.

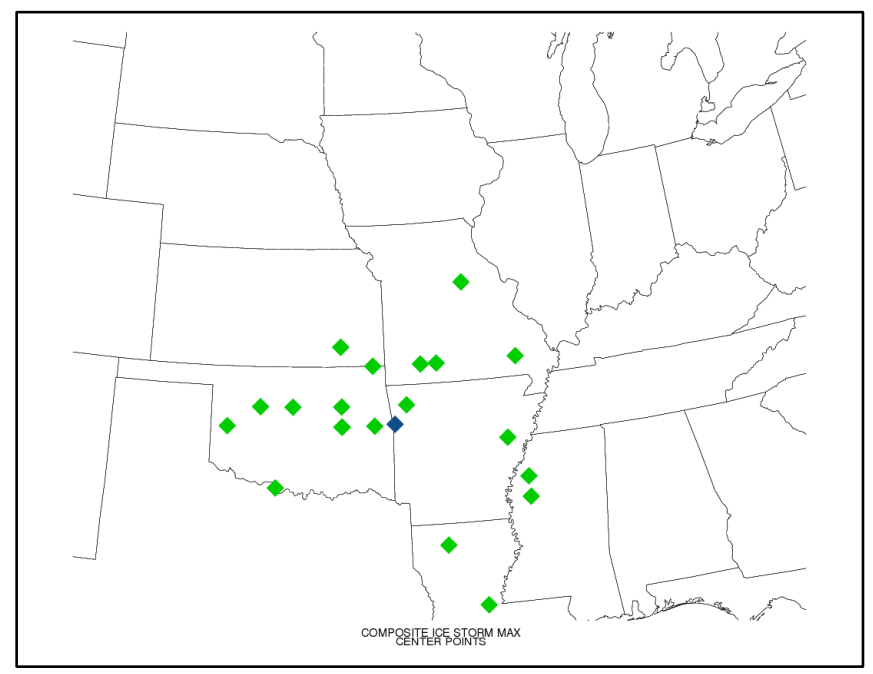

Figure 2. Center composite points at the maximum-coverage time for all 20 events (green) and average center composite point (blue).

The composite-analysis procedure in this paper will apply a system-relative methodology similar to Moore et al. (2003) and Gosselin et al. (2011). In this approach, system-relative composites capture the environment relative to a key feature(s) of the system. For the Midwest heavy-snow study in Gosselin et al. (2011), the key feature was the center of the $850-\mathrm{hPa}$ cyclone. As discussed in the previous section, past research on ice storms noted the importance of both the near-surface cold layer and the elevated warm layer. The near-surface cold layer easily can be 


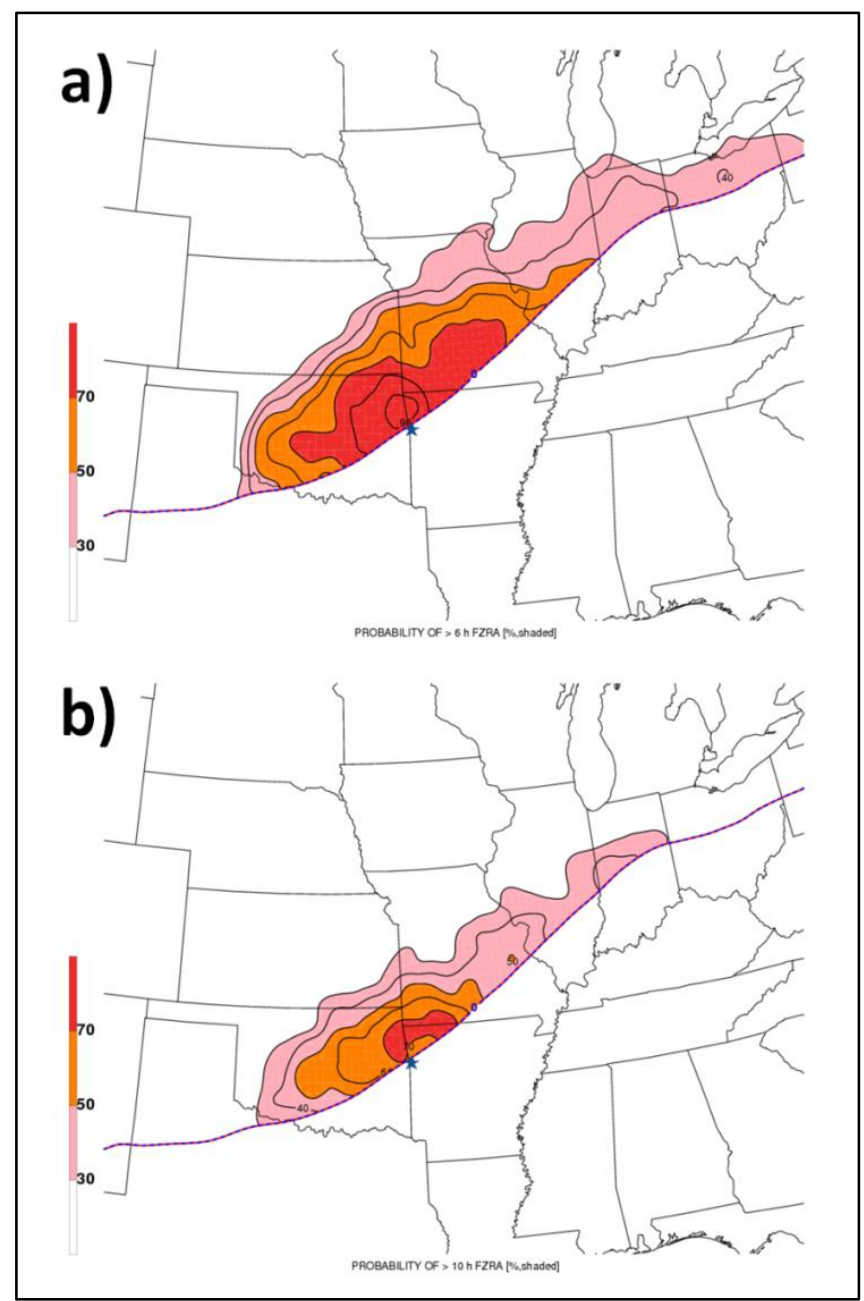

Figure 3. Probability (shaded, \%) of a surface observation reporting (a) $>6 \mathrm{~h}$ of freezing rain and (b) $>10 \mathrm{~h}$ of freezing rain. The $2-\mathrm{m} 0^{\circ} \mathrm{C}$ isotherm at maximum-coverage time is given in both as a red-and-blue dashed line. The blue star represents the average center composite point.

identified from the $2-\mathrm{m} 0^{\circ} \mathrm{C}$ isotherm, while an inspection of the 20 cases found a consistent low-level moisture axis at $850 \mathrm{hPa}$ that was typically associated with the elevated warm layer and low-level jet. Consequently, the intersection of these two features defined the center point for the system-relative composite analysis and was obtained for each case at each time for the composite analysis. To display the composite fields within a geographical context, the system-relative composites are presented with the center point located at its average location. An example of the distribution of center points and the average location for the maximum-coverage time is shown in Fig. 2. The 20 ice storms were examined using both traditional (i.e., mean) and probabilistic (i.e., frequency analysis of median, quartiles, and threshold exceedance) composite-analysis measures since the probabilistic quantities are less sensitive to potential outliers and can help assess the consistency of the mean composite analysis.

\section{Composite analysis}

An important characteristic associated with the 20 ice storms is the duration of freezing rain and ice accumulation, which plays a significant role in these destructive events. Ice-storm duration was examined by computing the fraction of cases where surfaceobservation stations exceeded a threshold number of hours of freezing-rain reports (surface observations have an effective radius of $120 \mathrm{~km}$ since that was approximately the average spacing of stations in the domain). Although the spatial extent of the percentage of surface observations exceeding $6 \mathrm{~h}$ and $10 \mathrm{~h}$ of freezing rain shown in Fig. 3 is similar, freezing rain lasted for more than $10 \mathrm{~h}$ in $70 \%$ of the ice storms to the north and northeast of the composite center. These probabilities highlight the area where destructive freezing rain is most likely to occur given this particular pattern, and denote the area for concern and additional investigation. It is important to note that Fig. 3 does not imply there are 6 or $10 \mathrm{~h}$ of continuous freezing rain, and thus it is possible the precipitation could occur in multiple phases.

\section{a. Large-scale evolution}

At the composite ice-storm start time, the sea-level pressure field depicts a 1032-hPa area of high pressure centered along the North Dakota-South Dakota border (Fig. 4). The $2-\mathrm{m} 0^{\circ} \mathrm{C}$ isotherm extends from the panhandle of Texas northeastward into central Ohio, placing the northwestern half of the domain within the sub-freezing surface layer associated with the Arctic air mass. A quasi-stationary front extends from southeastern Texas northeastward into North Carolina. Over the central plains at $850 \mathrm{hPa}$ there is a broad trough and a $\sim 12.5-\mathrm{m} \mathrm{s}^{-1}$ ( $25 \mathrm{kt}$ ) low-level jet centered over southeastern Texas. At midlevels, a 500-hPa long-wave trough is located over the western United States, with southwest flow over the central United States. A $51-\mathrm{m} \mathrm{s}^{-1}$ (100 kt) upper-level jet streak at 300 $\mathrm{hPa}$ is anchored over the Great Lakes in a position where the right-entrance region is enhancing the largescale ascent centered over the domain. The direct thermal circulation (DTC), associated with the entrance region of the upper-level jet streak, enhances the ascent as warm and moist air parcels originating in 

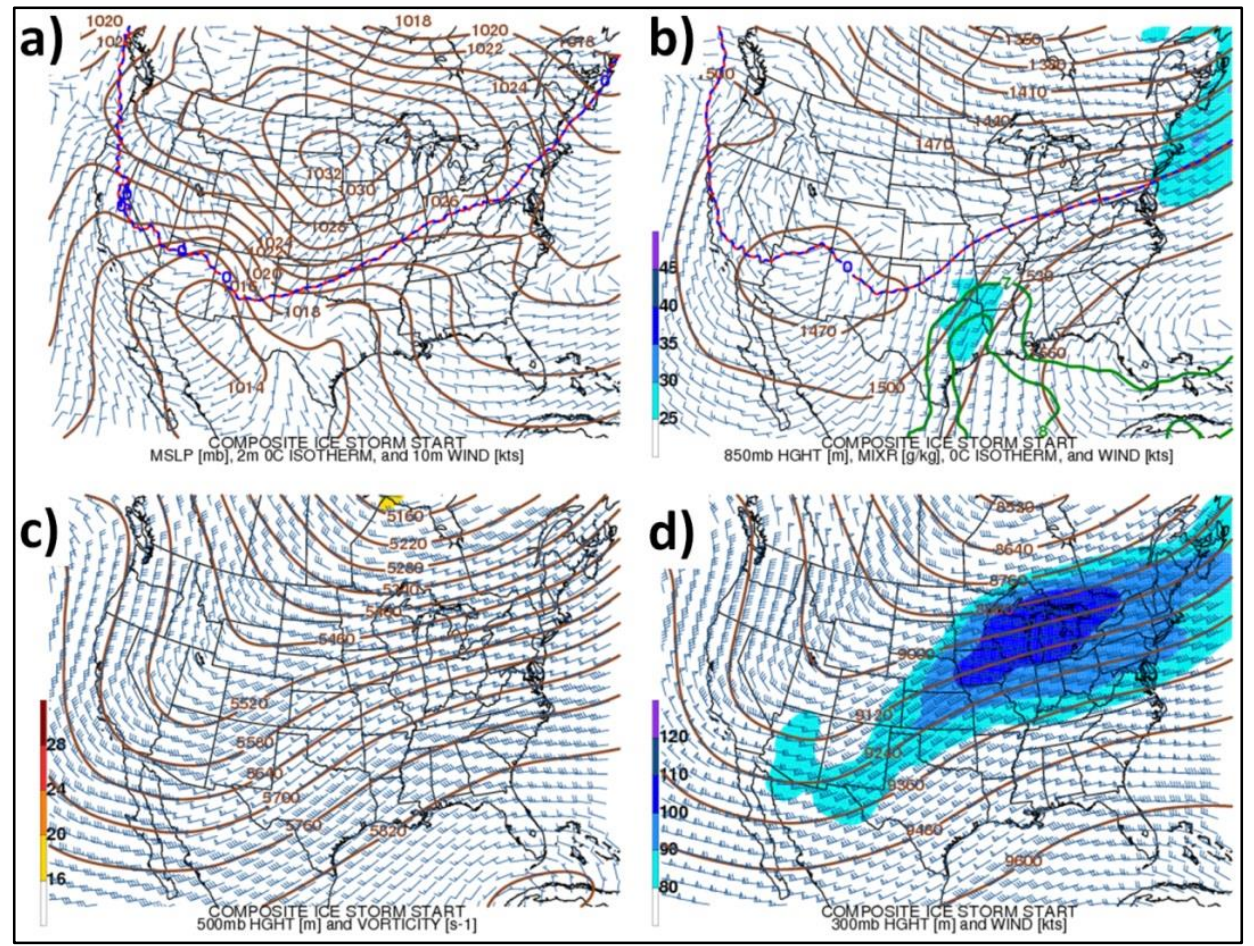

Figure 4. NARR mean composite analyses at the start time for (a) sea-level pressure (brown, $\mathrm{hPa}$ ), 2-m $0^{\circ} \mathrm{C}$ isotherm (red-and-blue dashed), and 10-m wind barbs (kt), (b) 850-hPa height (brown, $\mathrm{m}$ ), isotachs (shaded, kt), mixing ratio (green, $\mathrm{g} \mathrm{kg}^{-1}$ ), $0^{\circ} \mathrm{C}$ isotherm (red-and-blue dashed), and wind barbs (kt), (c) 500-hPa height (brown, m), absolute vorticity (shaded, $10^{-5} \mathrm{~s}^{-1}$ ), and wind barbs (kt), and (d) 300-hPa height (brown, m), isotachs (shaded, kt), and wind barbs (kt).

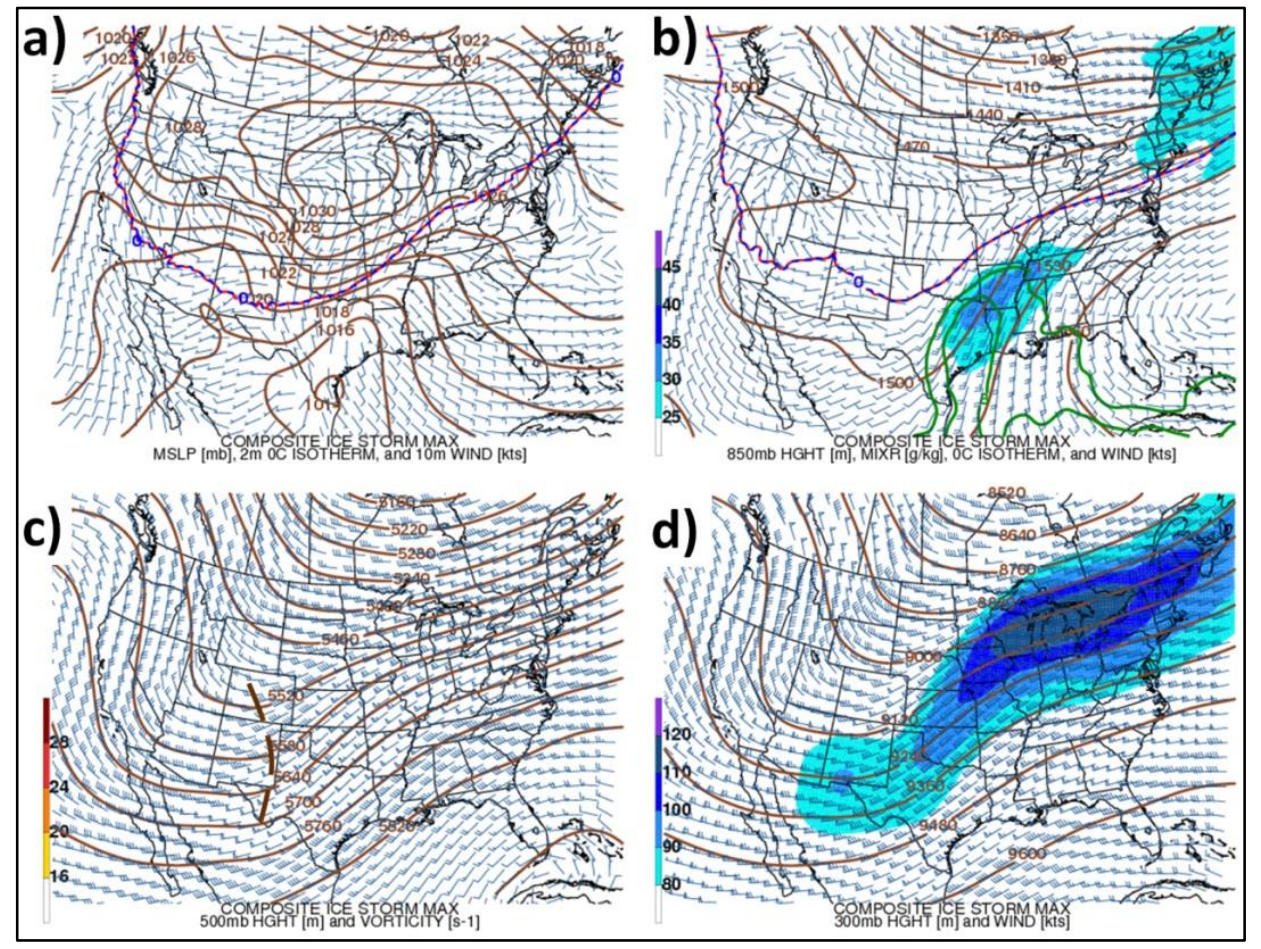

Figure 5. Same as Fig. 4 except for the composite at the maximum-coverage time. Brown dashed line in (c) indicates the position of a short-wave trough. 
low levels well south of the jet streak ascend isentropically into the entrance region. The location of the entrance region suggests this isentropic ascent originates in the lower levels near and around the Gulf of Mexico; consequently, the air mass in this region will supply the warm moist air needed to produce an elevated warm layer as well as precipitation. Southerly flow evident at $850 \mathrm{hPa}$ with the development of a low-level jet coincides with higher mixing ratios that extend north into the southern United States. Descent on the northern side of the upper-level jet streak is located in a position that supports high pressure and northerly winds at the surface in association with the sub-freezing Arctic air mass already in place, completing the DTC. Therefore, at the composite icestorm start time, the environment is already conducive to freezing precipitation similar to other studies (e.g., Robbins and Cortinas 2001).

At the composite ice-storm maximum-coverage time, the area of high pressure has weakened slightly to $1030 \mathrm{hPa}$, and is now centered along the South Dakota-Minnesota border (Fig. 5). The 2-m $0^{\circ} \mathrm{C}$ isotherm now extends from the Red River Valley northeastward into central Ohio, expanding the coverage of the sub-freezing surface layer to the south. The quasi-stationary front still extends from southeastern Texas northeastward into the Ohio Valley. Within the sub-freezing surface layer there is a general increase in the northerly surface winds from $2.5 \mathrm{~m} \mathrm{~s}^{-1}(5 \mathrm{kt})$ at the start time to $5 \mathrm{~m} \mathrm{~s}^{-1}(10 \mathrm{kt})$ at the maximum-coverage time. The broad $850-\mathrm{hPa}$ trough is still located over the central plains, with a $15.5-\mathrm{m} \mathrm{s}^{-1}$ (30 kt) low-level jet now centered over southeastern Arkansas. Examination of the composite low-level thermal profile depicts warm-air advection at $850 \mathrm{hPa}$ above the sub-freezing surface layer (Fig. 6) as the $850-\mathrm{hPa} 0^{\circ} \mathrm{C}$ isotherm is positioned well north of the $2-\mathrm{m} 0^{\circ} \mathrm{C}$ isotherm (cf. Figs. 5b and 6). The 500-hPa long-wave trough still remains over the western United States, although there is evidence of a lead short-wave trough advancing into the central United States (annotated in Fig. 5c). This implies multiple rounds of precipitation and enhanced large-scale lift is possible with the lead short-wave trough and another with the long-wave trough. The upper-level jet streak has strengthened in intensity and coverage, while showing evidence of back-building over the central plains as the 300-hPa trough still remains locked in over the western United States. Back-building of the composite upper-level jet streak may be due to air parcels accelerating as they experience diabatic effects from the release of latent heat during condensation within a highly sheared environment near and north of the lowlevel frontal zone (Market 1999).

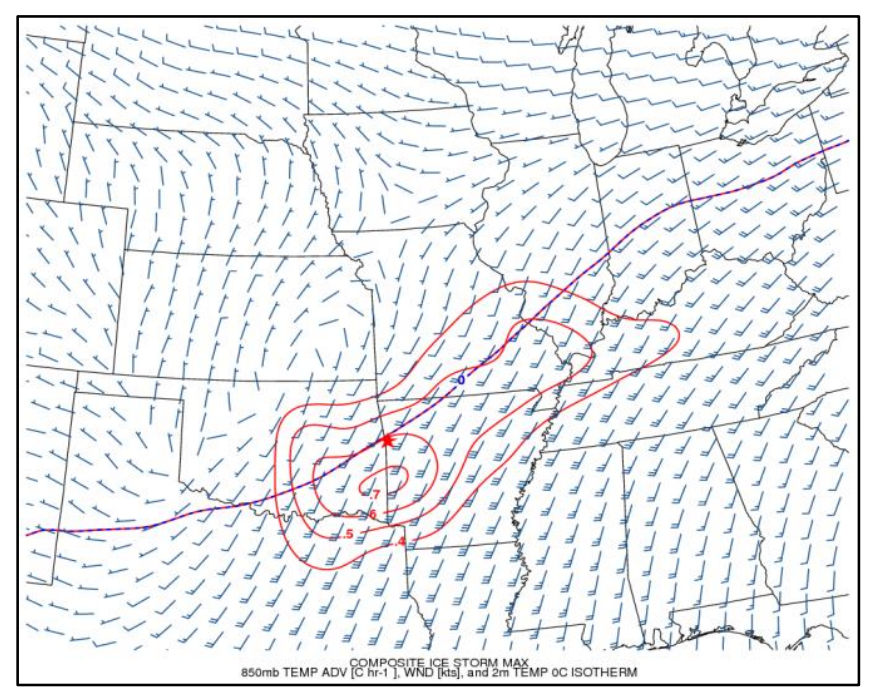

Figure 6. NARR mean composite analysis at the maximumcoverage time for $850-\mathrm{hPa}$ warm-air advection (red, ${ }^{\circ} \mathrm{C} \mathrm{h}^{-1}$ ) and $850-\mathrm{hPa}$ wind barbs (kt). Red star and $0^{\circ} \mathrm{C}$ isotherm same as in Fig. 3.

Over central Mississippi a 1014-hPa area of low pressure has formed at the composite end time (Fig. 7), where a warm front extends northeastward from the low pressure into central New York and a cold front extends southward into the Gulf of Mexico. The area of high pressure over the northern plains continues to weaken to $1024 \mathrm{hPa}$, and there has been a slight southeastward shift of the $2-\mathrm{m} 0^{\circ} \mathrm{C}$ isotherm since the maximum-coverage time. A more defined $850-\mathrm{hPa}$ trough now exists over the mid-Mississippi Valley and the axis of the strengthening low-level jet has shifted eastward into the southeastern and mid-Atlantic states. The 500-hPa long-wave trough has advanced into the central United States, and similarly, the $300-\mathrm{hPa}$ trough and jet streak also have progressed eastward, which suggests the large-scale ascent is mainly centered over the southeastern United States.

A cross section taken from Topeka, Kansas, to Baton Rouge, Louisiana, illustrates the mean vertical structure of these events at the composite maximumcoverage time (Fig. 8). Above the sub-freezing surface layer, a well-defined saturated elevated warm layer with a maximum depth of around $220 \mathrm{hPa}$ is present. Within this thermal profile, the presence of an ageostrophic DTC suggests convergence at the nose of 


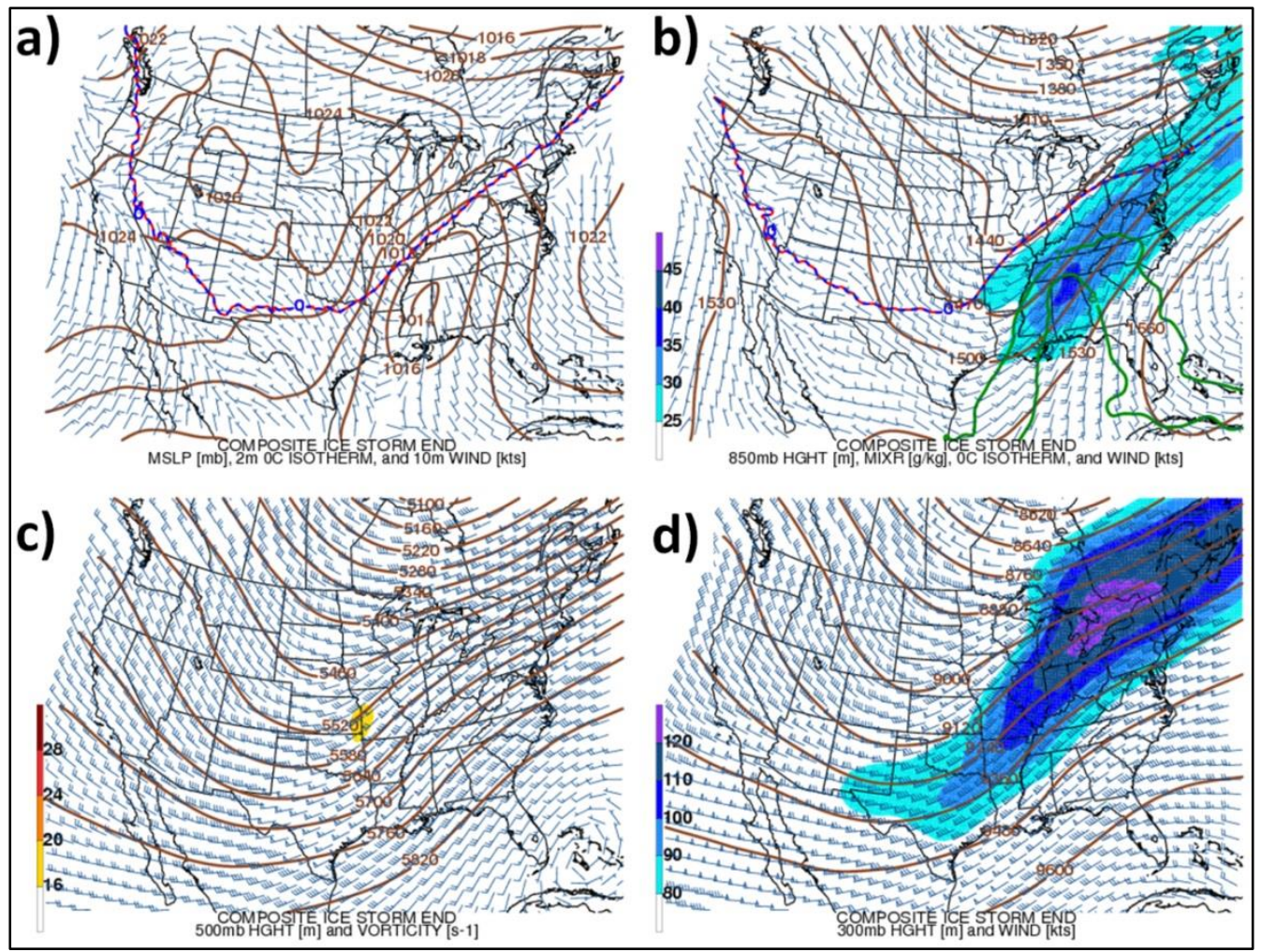

Figure 7. Same as Fig. 4 except for the composite at the end time.

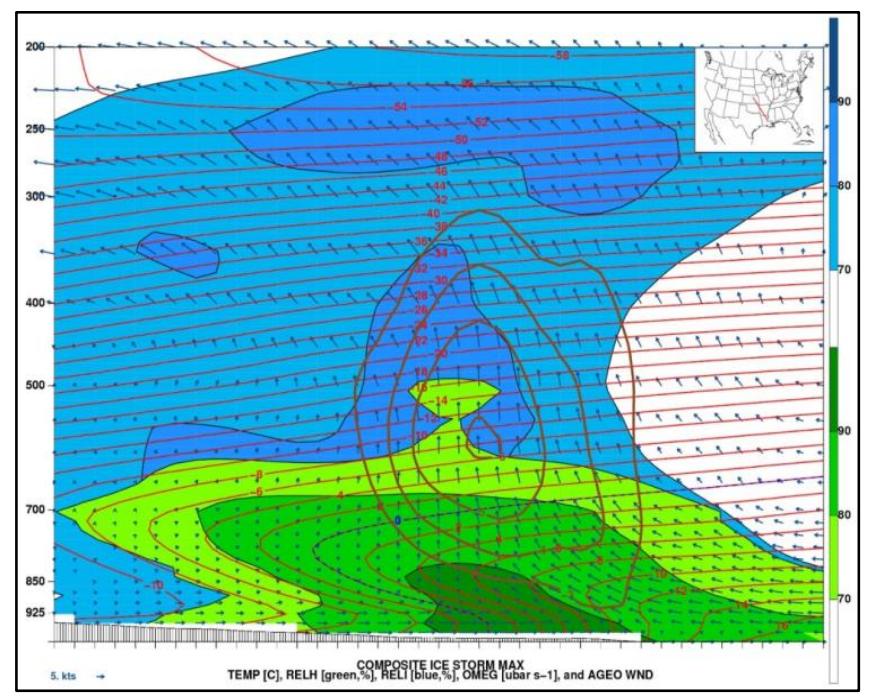

Figure 8. NARR mean composite cross section at the maximumcoverage time for temperature (red, ${ }^{\circ} \mathrm{C}$ ), $0^{\circ} \mathrm{C}$ isotherm (red-andblue dashed), relative humidity with respect to water (green, \%), relative humidity with respect to ice (blue, \%), omega (brown, $10^{-3}$ $\mathrm{Pa} \mathrm{s}^{-1}$ ), and ageostrophic vectors (kt).

the low-level jet and divergence aloft associated with the right-entrance region of the $300-\mathrm{hPa}$ jet streak. This results in (1) strong vertical motion that is maximized at $600 \mathrm{hPa}$ and (2) an environment sufficient for efficient precipitation formation.

Due to the importance of the coupling of the upper- and lower-tropospheric jet-streak in providing ageostrophic ascent and the transport of warm moist air poleward, the $300-$ and $850-\mathrm{hPa}$ jet streaks at the maximum-coverage time also were observed at the 25th and 75th percentiles (Fig. 9). Although still present, the 25th percentile isotachs have a downstream jet streak (Fig. 9a) that is $5.0-7.5 \mathrm{~m} \mathrm{~s}^{-1}$ (10-15 kt) weaker (i.e., $75 \%$ of the cases had wind values $\geq$ to those shown) than the mean composite, and an inspection of the 20 cases found that several of the events with weaker upper-level flow had the jet streak positioned further to the southwest. Isotach percentiles are shown in Figs. 9c and d for $850 \mathrm{hPa}$. Although the most obvious difference between the 25th and 75th percentiles is the size and strength of the low-level wind field, each ice storm is associated with a low-level jet in a similar location and orientation. The variability in the strength of the $300-$ and $850-\mathrm{hPa}$ jet streaks suggests the magnitude of these features varies from case to case but that their presence is a robust signal in the ice-storm events. 

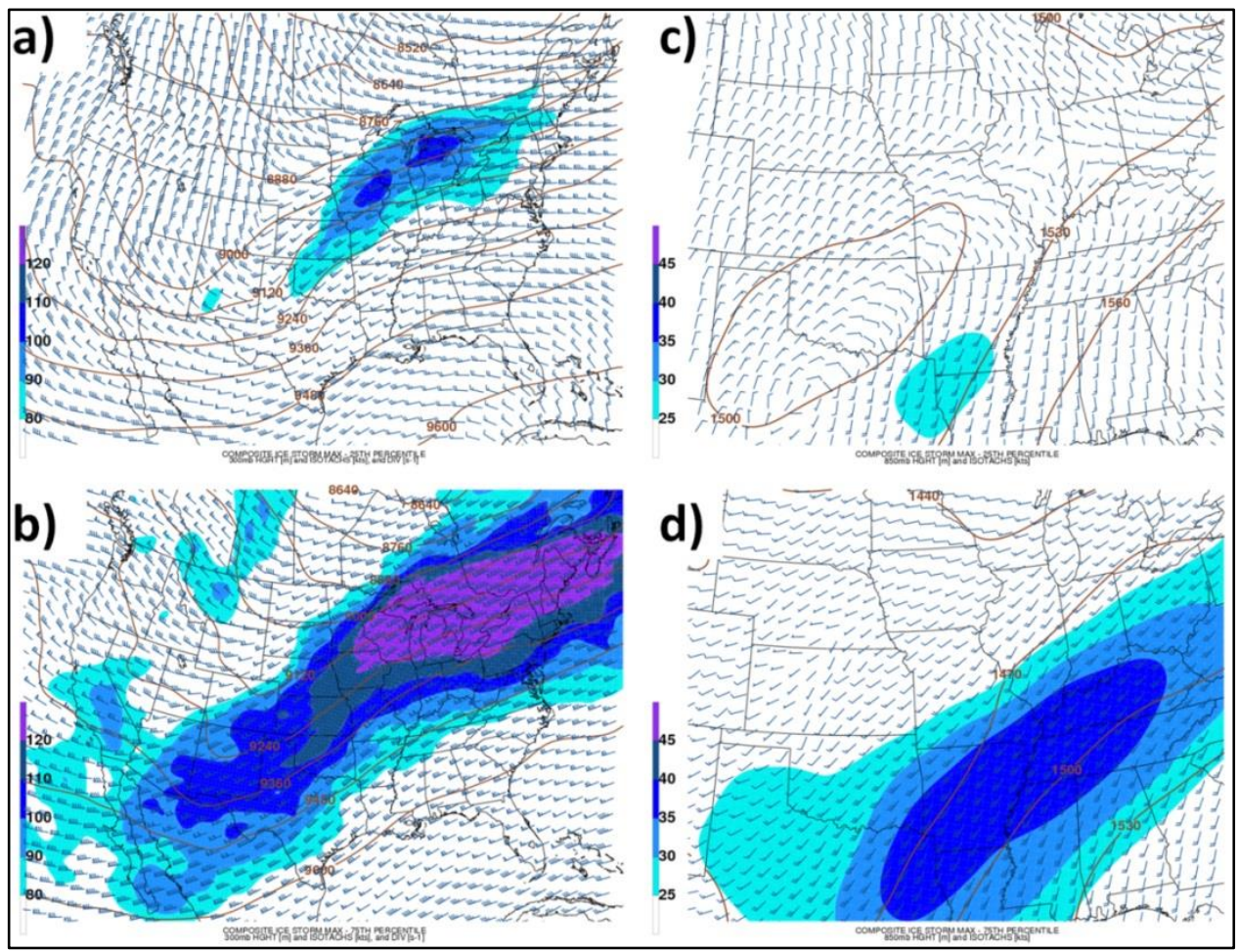

Figure 9. NARR probabilistic composite analysis at the maximum-coverage time for the (a) 25th and (b) 75th percentile of 300-hPa height (brown, m), isotachs (shaded, kt), and wind barbs (kt); and for the (c) 25th and (d) 75th percentile of 850-hPa height (brown, m), isotachs (shaded, kt), and wind barbs (kt).

\section{b. Sub-freezing surface-layer characteristics}

One of the factors that contributed to the devastating ice accumulations in these events was their long duration. However, in order for freezing rain to be sustained, the surface cold layer needs to be maintained throughout the event since latent heat of fusion from the freezing precipitation, and sensible heat, contribute to the warming of this layer. To partially offset this warming and thus maintain belowfreezing conditions at the surface, cold-air advection $\left(\sim 1^{\circ} \mathrm{C} 3 \mathrm{~h}^{-1}\right)$ is present along the $2-\mathrm{m} 0^{\circ} \mathrm{C}$ isotherm at the maximum-coverage time (Fig. 10a). Furthermore, since the cold layer is relatively saturated (Fig. 8), evaporational cooling can only impact this layer if dry air is advected into the region. Figure $10 \mathrm{~b}$ shows cooler wet-bulb temperatures being advected into this region, which would cause the air temperature to decrease to maintain saturation within the layer. Consequently, the effects of dry-air advection are comparable to temperature advection in maintaining the surface cold layer $\left(\sim 0.5^{\circ} \mathrm{C} 3 \mathrm{~h}^{-1}\right)$. The two processes, along with a northerly low-level component of the ageostrophic wind within the DTC, increase the potential for the sub-freezing surface layer to be sustained for the duration of the event, which would lead to a prolonged period of freezing rain and greater ice accumulations.

Even with the relatively coarse low-level vertical resolution of $25 \mathrm{hPa}$ in the NARR data, the coldest temperatures are slightly above the surface within the near-surface cold layer, a finding consistent with Rauber et al. (2001). When the coldest near-surface temperatures reach about $-5^{\circ} \mathrm{C}$, Stewart and Crawford (1995) found that droplets falling into the surface cold layer refreeze into ice pellets. Zerr (1997) found by investigating soundings during ice-pellet events that temperatures in the cold layer were less than $-5^{\circ} \mathrm{C}$ and depths were greater than $700 \mathrm{~m}$. The location of this temperature in the northern portion of the region could roughly be used as the furthest northern extent of the freezing rain, assuming that precipitation is falling and temperatures in the elevated warm layer are sufficiently warm enough to completely melt the precipitation. At the maximum-coverage time, the $-5^{\circ} \mathrm{C}$ isotherm (derived from the coldest temperature between the surface and $700 \mathrm{hPa}$ ) is located about 150 $\mathrm{km}$ north of the $2-\mathrm{m} 0^{\circ} \mathrm{C}$ isotherm (Fig. 11). Locations 


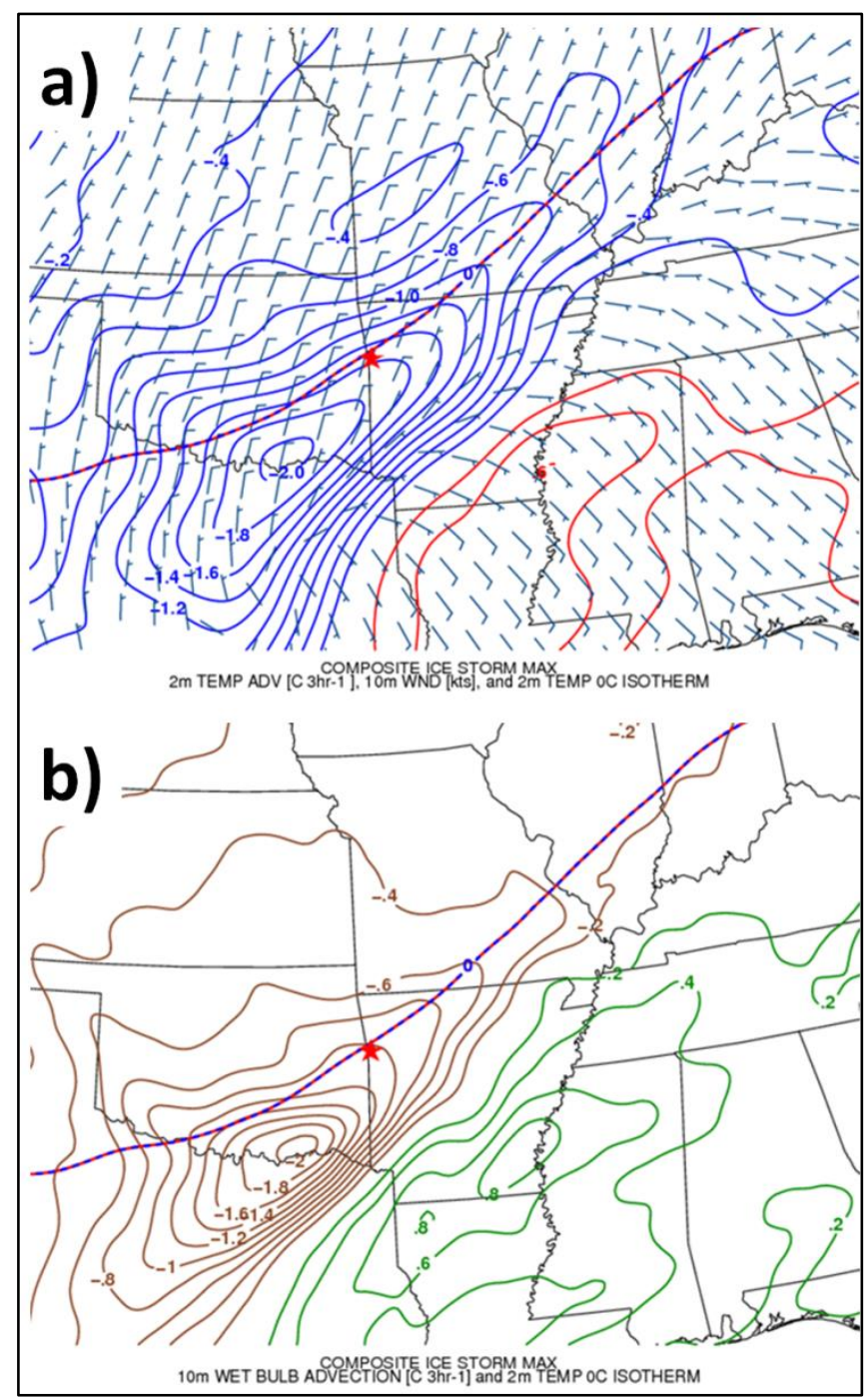

Figure 10. NARR mean composite analysis at the maximumcoverage time for (a) 2-m cold-air advection (blue, ${ }^{\circ} \mathrm{C} 3 \mathrm{~h}^{-1}$ ), warm-air advection (red, ${ }^{\circ} \mathrm{C} 3 \mathrm{~h}^{-1}$ ), and $10-\mathrm{m}$ wind barbs (kt) and (b) 10-m cold wet-bulb advection (brown, ${ }^{\circ} \mathrm{C} 3 \mathrm{~h}^{-1}$ ) and warm wetbulb advection (green, ${ }^{\circ} \mathrm{C} 3 \mathrm{~h}^{-1}$ ). Red stars and $0^{\circ} \mathrm{C}$ isotherms same as in Fig. 3.

at the surface north of the $-5^{\circ} \mathrm{C}$ isotherm encounter both colder temperatures in the sub-freezing surface layer and lower temperatures in the elevated warm layer. At these locations, ice crystals falling into this layer have a greater chance of only partially melting, as well as a greater chance of refreezing into sleet within the sub-freezing surface layer. This is supported by the spatial extent of the percentage of surface observations having at least one sleet or ice pellet report during the six hours centered around the maximum-coverage time (Fig. 11). To the north of the composite center the axis of highest sleet and ice pellet probabilities align with the $-5^{\circ} \mathrm{C}$ isotherm.

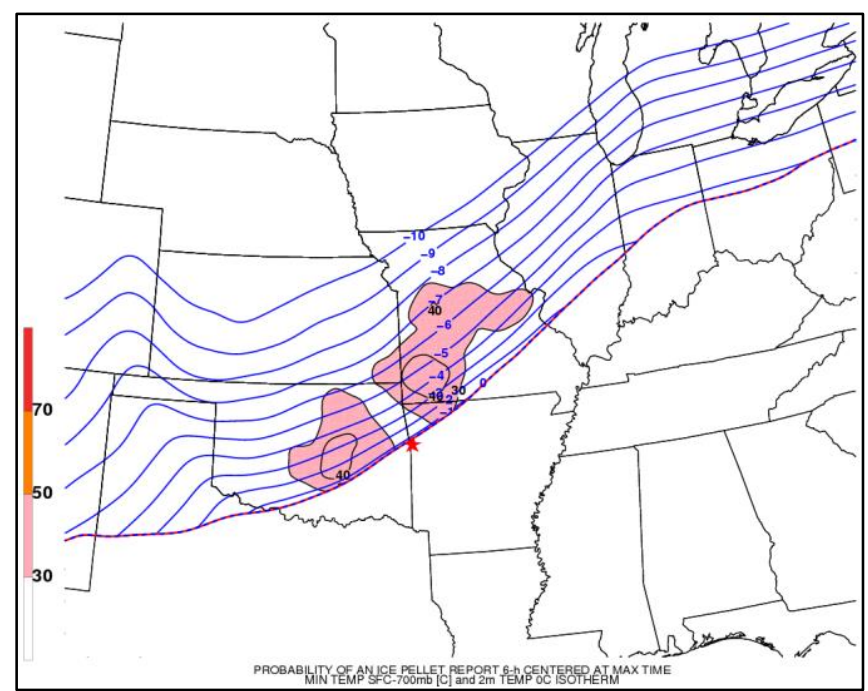

Figure 11. NARR mean composite analysis at the maximumcoverage time for minimum temperature between the surface and $700 \mathrm{hPa}$ (blue, ${ }^{\circ} \mathrm{C}$ ) and the probabilistic composite analysis of a surface observation reporting ice pellets or sleet during the six hours centered around the maximum-coverage time (shaded, \%). Red star and $0^{\circ} \mathrm{C}$ isotherm same as in Fig. 3. Only temperature contours $>-10^{\circ} \mathrm{C}$ are shown and the contours south of the $2-\mathrm{m}^{\circ} \mathrm{C}$ isotherm are clipped.

\section{c. Elevated warm-layer characteristics}

The elevated warm layer is susceptible to the same thermodynamic and microphysical processes as the sub-freezing surface layer. As found in previous studies, warm-air advection at $850 \mathrm{hPa}$ is present above the sub-freezing surface layer. The $850-\mathrm{hPa}$ warm-air advection composite at the time of maximum coverage (refer back to Fig. 6) shows that the strongest warm-air advection is located south of the sub-freezing surface layer with weaker values extending northward above the area of interest. Coincident with warm-air advection, $850-\mathrm{hPa}$ mixing ratios and moisture transport vectors at the maximum-coverage time (Fig. 12) suggest that moisture convergence and isentropic lift in the elevated warm-layer assist in the generation of liquid water, which in turn aid in the development of precipitation due to collision and coalescence. Finally, any cooling that occurs as ice crystals fall and melt within the warm layer or through large-scale vertical motion is offset by the warm-air advection.

Similar to Fig. 8, a cross section of potential temperature reveals that the center of the elevated warm layer can be defined by the $294-\mathrm{K}$ isentropic surface (Fig. 13). An analysis of that isentropic level can reveal additional characteristics of the air streams that define the elevated warm layer. Furthermore, since the system is evolving slowly, the streamlines 


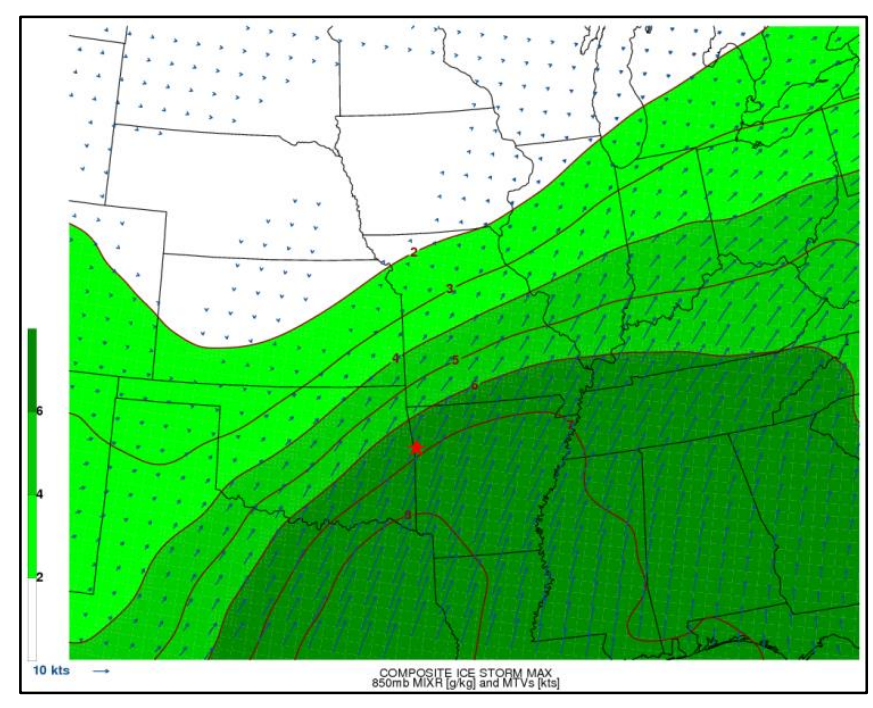

Figure 12. NARR mean composite analysis at the maximumcoverage time for $850-\mathrm{hPa}$ mixing ratios (shaded, $\mathrm{g} \mathrm{kg}^{-1}$ ) and moisture transport vectors (kt). Red star same as in Fig. 3.

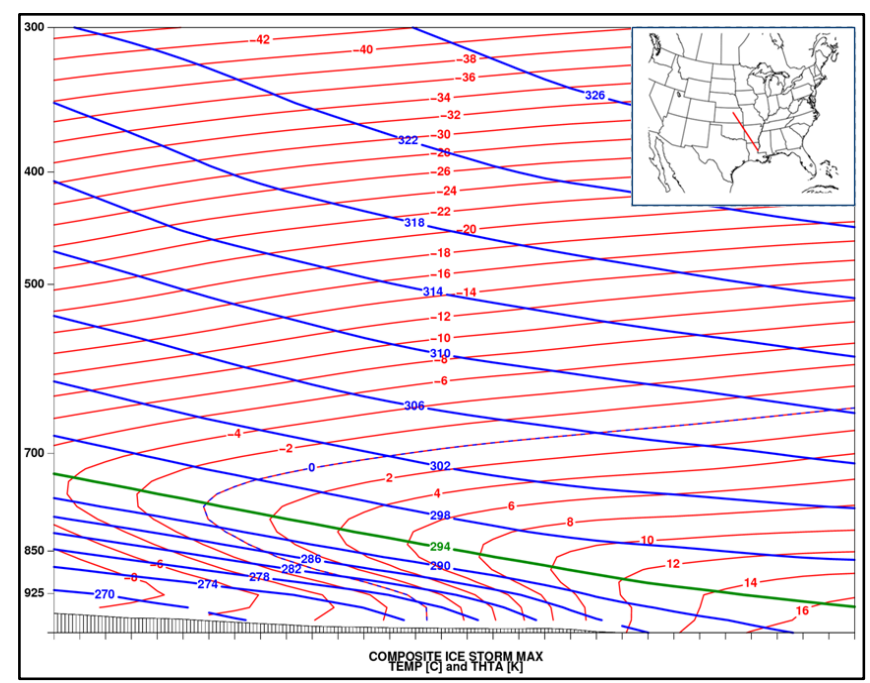

Figure 13. NARR mean composite cross section at the maximumcoverage time for temperature (red, ${ }^{\circ} \mathrm{C}$ ), $0^{\circ} \mathrm{C}$ isotherm (red-andblue dashed), potential temperatures (blue, K), and 294-K potential temperature (green).

can be trajectory approximations in the vicinity of the elevated warm layer. Flow on the $294-\mathrm{K}$ potential temperature surface shown in Fig. 14 suggests that air parcels over the central United States appear to have two origins - one in the Gulf of Mexico and the other across the Mexican Plateau ( $750 \mathrm{hPa}$, not shown). The moisture content of air parcels from the Gulf of Mexico is $8-10 \mathrm{~g} \mathrm{~kg}^{-1}$ higher than those originating from the Mexican Plateau. In addition, precipitable water values range from $19.05-25.40 \mathrm{~mm}(0.75-1.00$ in) over the southern portion of the domain, which for this time of year is approximately two standard deviations above normal (based on the precipitable water climatology around Springfield, Missouri; Bunkers 2010). Ultimately, this composite analysis portrays warm, moist air moving north while gently ascending into the elevated warm layer. The maximum temperature between the surface and $500 \mathrm{hPa}$ has values ranging from $0-7^{\circ} \mathrm{C}$ (Fig. 15a) that occur between $850-825 \mathrm{hPa}$ (Fig. 15b). The depth of the elevated warm-layer averages $\sim 1800 \mathrm{~m}$ or $200 \mathrm{hPa}$ (Figs. 15c,d), which is consistent with the depths found by Robbins and Cortinas (2001) to be sufficient for ice-crystal melting; these depths cover a large portion of the sub-freezing surface layer. Finally, as the freezing rain subsides, cold-air advection develops upstream of the $850-\mathrm{hPa}$ trough axis as it advances to the east - eroding the elevated warm layer in the process.

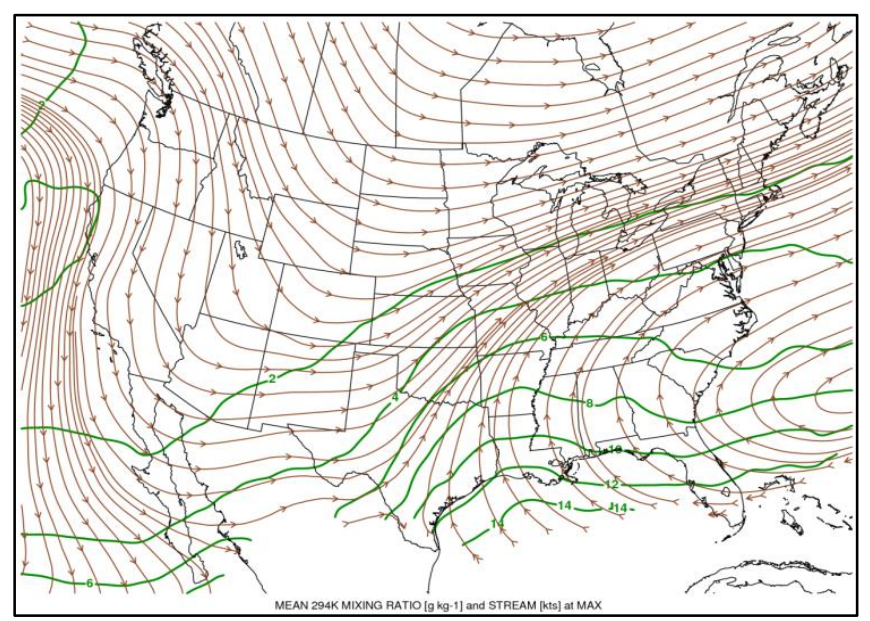

Figure 14. NARR mean composite analysis at the maximumcoverage time for mixing ratio (green, $\mathrm{g} \mathrm{kg}^{-1}$ ) and streamlines (black, kt) on the 294-K potential temperature surface.

Regions conducive to freezing rain are associated with a juxtaposition of a sub-freezing cold layer and a significant elevated warm layer of $3^{\circ} \mathrm{C}$ or more (e.g., Robbins and Cortinas 2001). Robbins and Cortinas also found that the $2-\mathrm{m} 0^{\circ} \mathrm{C}$ isotherm was generally located between 15 and $100 \mathrm{~km}$ to the south of the freezing-rain site with an average position of the 850$\mathrm{hPa} 0^{\circ} \mathrm{C}$ isotherm between 100 and $300 \mathrm{~km}$ to the north. To assess the presence of these conditions, combined probabilities of the maximum temperature between the surface and $500 \mathrm{hPa}$ greater than $3^{\circ} \mathrm{C}$ with a surface temperature below $0^{\circ} \mathrm{C}$ were computed in Fig. 16. This analysis revealed that, to the north of the composite center in an elongated corridor oriented southwest-to-northeast, $70 \%$ of the ice storms were associated with the conditions described by Robbins 


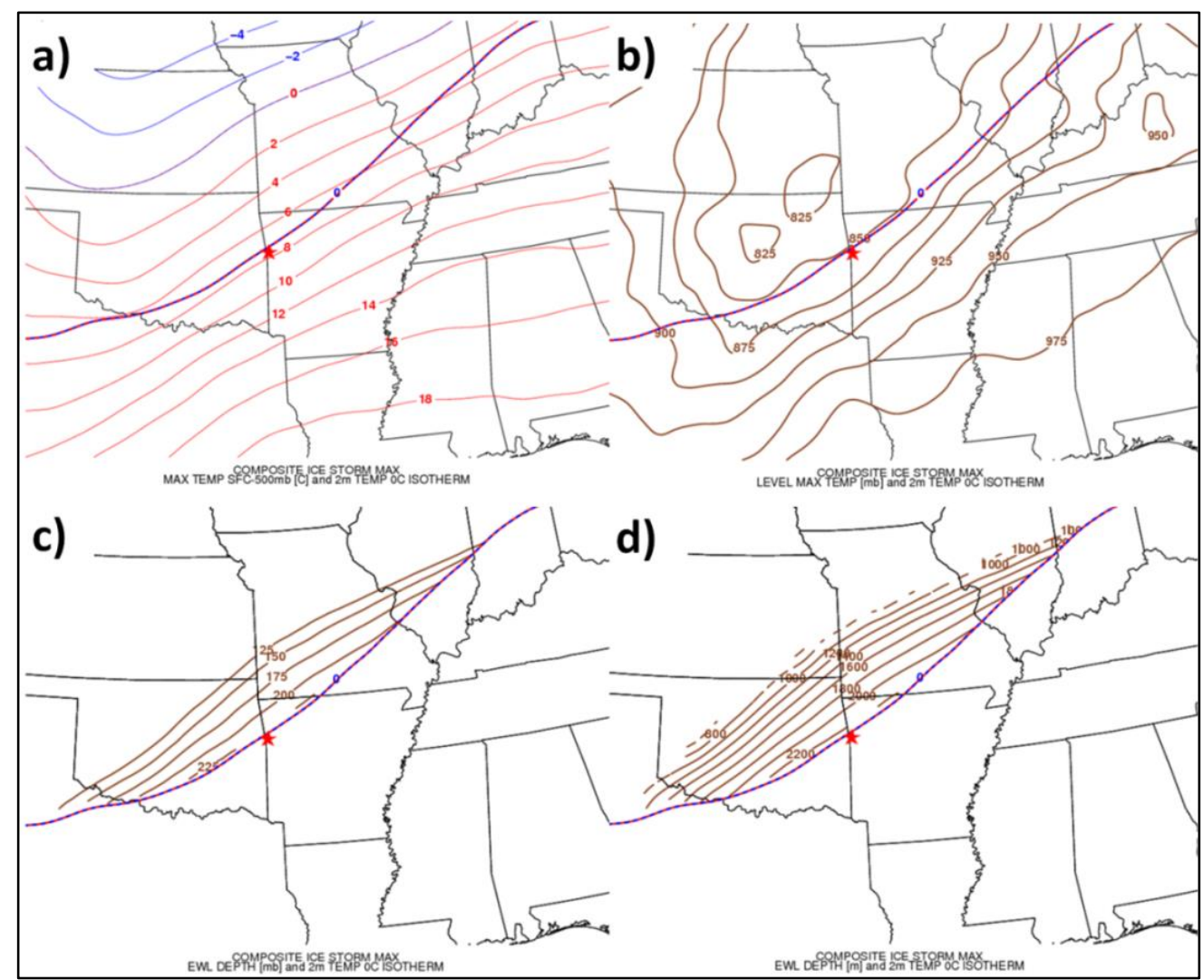

Figure 15. NARR mean composite analysis at the maximum-coverage time for (a) maximum temperature between the surface and $500 \mathrm{hPa}$ (red and blue, ${ }^{\circ} \mathrm{C}$ ), (b) level of the maximum temperature between the surface and $500 \mathrm{hPa}$ (brown, $\mathrm{hPa}$ ), (c) depth of elevated warm layer (brown, $\mathrm{hPa}$ ), and (d) depth of elevated warm layer (brown, m). Red stars and $0^{\circ} \mathrm{C}$ isotherms same as in Fig. 3.

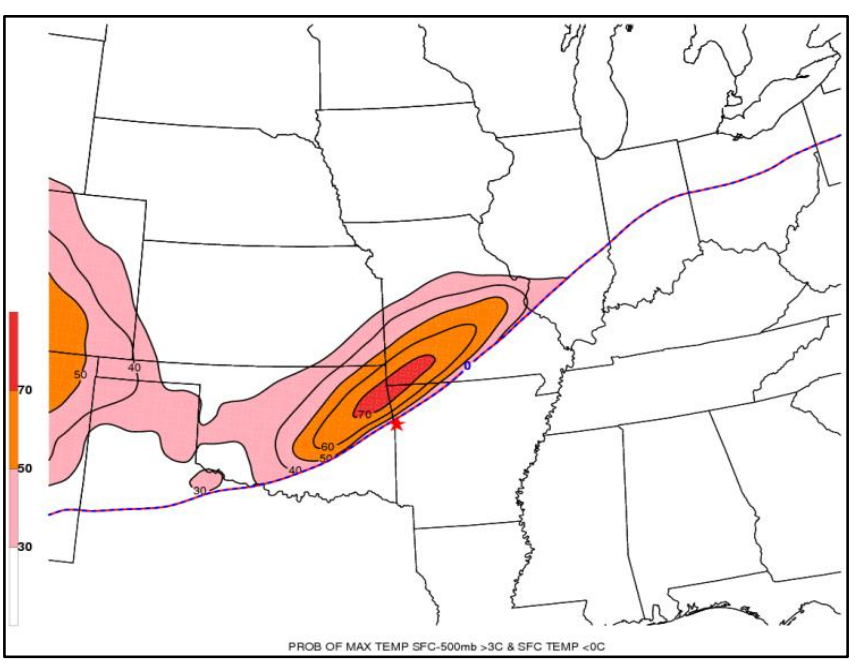

Figure 16. NARR probabilistic composite analysis at the maximum-coverage time of the intersection of the 2-m temperature $<0^{\circ} \mathrm{C}$ and maximum temperature between the surface and $500 \mathrm{hPa}$ $>3^{\circ} \mathrm{C}$ (shaded, \%). Red star and $0^{\circ} \mathrm{C}$ isotherm same as in Fig. 3 .

and Cortinas. When examining hourly surface observations for each ice storm, it was not uncommon to see freezing-rain observations clustered in a similar orientation relative to each ice storm's center point. The robust signal in the probabilities supports previous research and adds value to the composite results for the presence of an elevated warm layer with temperatures exceeding the threshold to melt ice crystals above an area of sub-freezing surface temperatures.

\section{Summary and conclusions}

A climatology and composite evolution of major ice storms in and around the Springfield, Missouri, CWA was presented, and a conceptual model of the ice-storm maximum-coverage time is shown in Fig. 17. The composite results largely confirm previous research on ice storms in the central United States and suggest that major ice storms are associated with an identifiable synoptic-scale environment. Surface high pressure is centered over the northern plains with a cold front and sub-freezing temperatures located through the northern half of the eastern United States. 


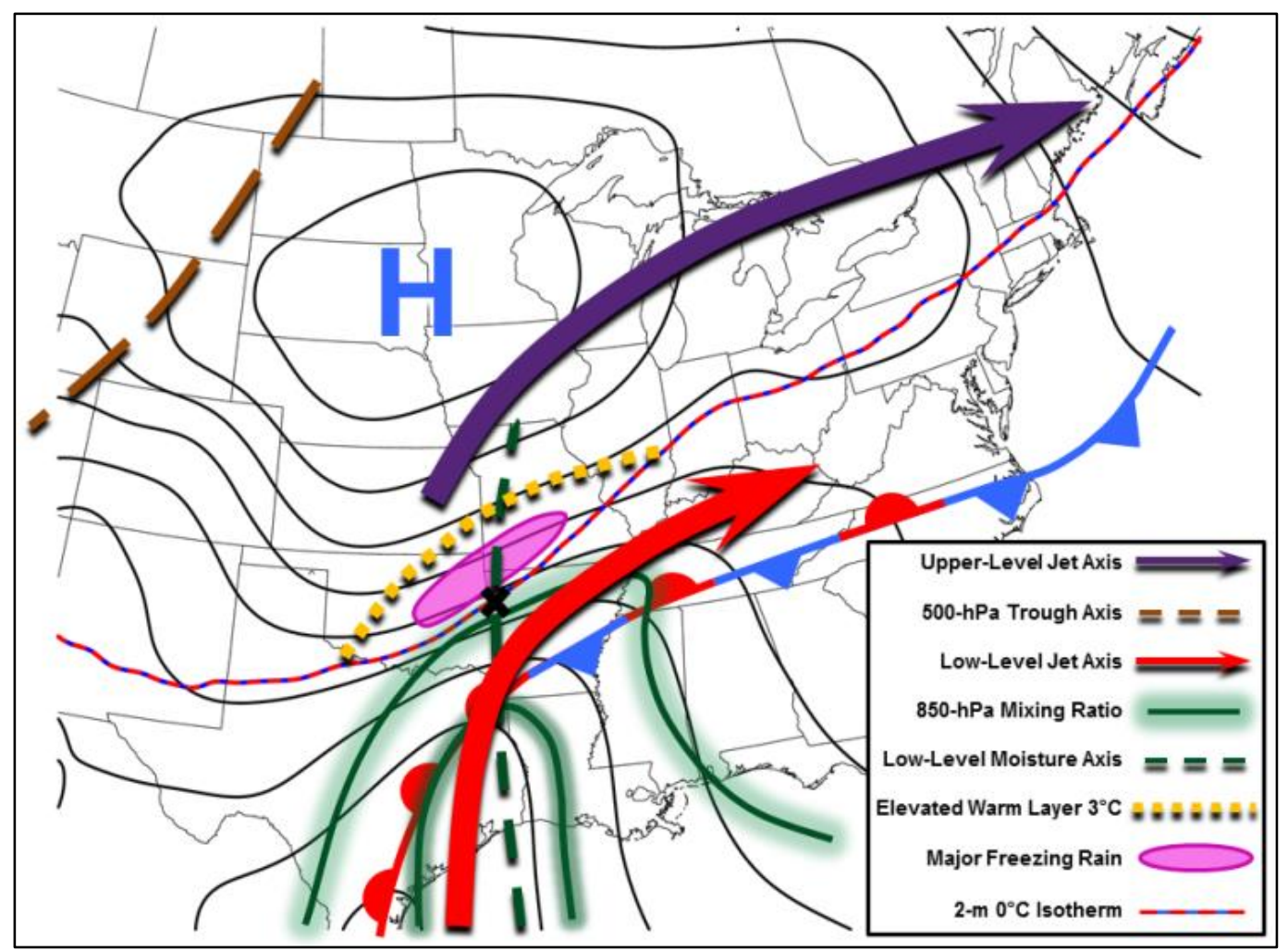

Figure 17. Conceptual model of the synoptic and mesoscale environment for major ice storms in the central United States. Features include the following: 300-hPa jet axis (purple arrow); 500-hPa trough axis (brown dashed); 850-hPa jet axis (red arrow), mixing ratios (green solid), and moisture axis (green dashed); $3^{\circ} \mathrm{C}$ isotherm between the surface and $500 \mathrm{hPa}$ (yellow dashed); highest probability of major freezing rain (pink shaded); $2-\mathrm{m}^{\circ} \mathrm{C}$ isotherm (red-and-blue dashed); and sea-level pressure (black solid).

The front stalls out to the south and there is an inverted trough from Texas extending into Kentucky. A strong low-level jet, which is enhanced by an upper-level jet streak and associated DTC, bisects the southwestnortheast oriented surface thermal gradient to the east of a weak $850-\mathrm{hPa}$ trough. The low-level jet is responsible for supplying warm and moist air above the sub-freezing surface layer which melts frozen precipitation falling into it from above. An upper-level long-wave trough is centered over the southwestern United States, and there is evidence of a lead shortwave trough ejecting into the plains, which suggests multiple rounds of enhanced vertical motion and precipitation.

Probabilities of the ice-storm events exceeding certain thresholds also were examined. At the $2-\mathrm{m} 0^{\circ} \mathrm{C}$ isotherm around the Missouri and Oklahoma border and extending to the northwest about $150 \mathrm{~km}$, there was an $80 \%$ probability of a freezing-rain observation. Furthermore, there was a $70 \%$ probability of an observation site reporting over ten hours of freezing rain near the composite center point. This suggests that the duration of the freezing rain may play a major role in the large ice accumulations. These results are supported by an examination of the elevated warmlayer maximum temperature. In $50 \%$ and $70 \%$ of the 20 ice-storm events, the elevated warm-layer maximum temperature exceeded $6^{\circ} \mathrm{C}$ and $3^{\circ} \mathrm{C}$, respectively, which past research has found to be more than sufficient to fully melt ice crystals.

To further understand and quantify the differences between major ice storms and those associated with less freezing rain (or null events), an avenue for future work would be to compare and contrast these sets of events using a similar methodology. This would increase the value of the presented regional conceptual model by highlighting atmospheric fields that may play a distinguishing role in major ice storms.

Acknowledgements. The authors express their sincere appreciation to COMET for their contributions to the funding of the project; Saint Louis University for supplying the equipment, data, and software needed to conduct the research; and the NWS in Springfield, Missouri, for their collaboration and cooperation. We also thank Ken Cook, 
Frank McDonough, and one anonymous reviewer for their helpful reviews, as well as Jeff Manion (NWS Central Region Headquarters) for technical editing.

\section{REFERENCES}

Bernstein, B. C., 2000: Regional and local influences on freezing drizzle, freezing rain, and ice pellet events. Wea. Forecasting, 15, 485-508.

Branick, M. L., 1997: A climatology of significant winter-type weather events in the Contiguous United States, 1982-94. Wea. Forecasting, 12, 193-207.

Bunkers, M. J., cited 2010: Precipitable water plots. National Weather Service, Rapid City, SD. [Available online at www.crh.noaa.gov/unr/?n=pw.]

Changnon, S. A., 2002: Characteristics of ice storms in the United States. J. Appl. Meteor., 42, 630-639.

, and T. R. Karl, 2003: Temporal and spatial variations of freezing rain in the contiguous United States: 1948-2000. J. Appl. Meteor., 42, 1302-1315.

Cortinas, J. V., Jr., B. Bernstein, C. C. Robbins, and J. W. Strapp, 2004: An analysis of freezing rain, freezing drizzle, and ice pellets across the United States and Canada: 1976-1990. Wea. Forecasting, 19, 377-390.

Czys, R. R., R. W. Scott, K. C. Tang, R. W. Przybylinski, and M. E. Sabones, 1996: A physically based, nondimensional parameter for discriminating between locations of freezing rain and ice pellets. Wea. Forecasting, 11, 591-598.

Gosselin, J. P., C. M. Gravelle, C. E. Graves, J. P. Gagan, F. H. Glass, 2011: Composite analysis of heavy snow events within the Springfield and St. Louis, Missouri National
Weather Service county warning areas. Natl. Wea. Dig., 35, 57-81.

Market, P. S., 1999: Jet streak modification via diabatic heating during periods of intense, cool-season precipitation. Ph.D. dissertation, Saint Louis University, 158 pp. [Available from Department of Earth and Atmospheric Sciences, Saint Louis University, 205 O'Neil Hall, 3642 Lindell Blvd., St. Louis, Missouri, 63108.]

Mesinger, F., and Coauthors, 2006: North American Regional Reanalysis. Bull. Amer. Meteor. Soc., 87, 343-360.

Moore, J. T., F. H. Glass, C. E. Graves, S. M. Rochette, and M. J. Singer, 2003: The environment of warm-season elevated thunderstorms associated with heavy rainfall over the central United States. Wea. Forecasting, 18, 861-878.

Rauber, R. M., L. S. Olthoff, M. K. Ramamurthy, D. Miller, and K. E. Kunkel, 2001: A synoptic weather pattern and sounding-based climatology of freezing precipitation in the United States east of the Rocky Mountains. J. Appl. Meteor., 40, 1724-1747.

Robbins, C. C., and J. V. Cortinas Jr., 2001: Local and synoptic environments associated with freezing rain in the contiguous United States. Wea. Forecasting, 17, 47-65.

Stewart, R. E., and P. King, 1987: Freezing precipitation in winter storms. Mon. Wea. Rev., 115, 1270-1280. , and R. W. Crawford, 1995: Some characteristics of the precipitation formed within winter storms over eastern Newfoundland. Atmos. Res., 36, 17-37.

, J. D. Marwitz, J. C. Pace, and R. E. Carbone, 1985: Characteristics through the melting layer of stratiform clouds. J. Atmos. Sci., 41, 3227-3237.

Zerr, R. J., 1997: Freezing rain: An operational and theoretical study. J. Appl. Meteor., 36, 1647-1661. 